373, 350). 272. $\mathrm{MS}(\mathrm{EI}): m / z 1025\left(M^{*}-\mathrm{Cp}^{*} .2 \%\right), 580\left(M / 2^{+}, 25\right), 135\left(\mathrm{Cp}^{*}\right.$ 100). Correct elemental analysis

Received: July 16, 1993 [Z 62191E] German version: Angew. Chem. 1993. 105. 1828

[1] W. Uhi. $Z$. Natuforseh. B 1988. 43. 1113.

[2] W. Uhl, A. Vester. Chem. Ber. 1993, 126, 941.

[3] H. Hoberg, S. Krause, Angew. Chem. 1976. 88. 760: Angew: Chem. Int. Ed. Engl. 1976, 15, 694: H. Hoberg. S. Krause, ibid. 1978, 90, 1013 and 1978. 17. 949.

[4] C. Dohmeier, C. Robl. M. Tacke. H. Schnöckel, Angew: Chem. 1991, 103 , 594: Angew. Chent. Int. Ed. Engl 1991, 30, 564

[5] W. Hiller, K.-W. Klinkhammer, W. Uhl, J. Wagner, Angew. Chem. 199I, 103. 182: Angen. Chem. Int. Ed. Engl. 1991, 30,179.

[6] N. Wiberg in Frontiers of Organosilic on Chemistry (Eds.: A. R. Bassindale. P. P. Gaspar). The Royal Society of Chemistry. Cambridge, 1991, p. 263; U. Schneider, R. Ahlrichs. H. Horn, A. Schäfer, Angew: Chem. 1992, 104, 327: Angerr. Chem. Int. Ed. Engl. 1992. 31, 353.

[7] M. Tacke. H. Schnöckel, Inorg. Chem. 1989, 28, 2895.

[8] S. Schulz. H. J. Koch. H. W. Roesky, M. Noltemeyer, H.-G. Schmidt, A. Heine. R. Herbst-Irmer, D. Stalke. G. M. Sheldrick, Chem, Ber. 1992, 125 1107

19] The physical and chemical properties of 1 described by Schnöckel et al. are slightly different from those found by us.

[10] A single-crystal $X$-ray structure analysis at $-120 \cdot \mathrm{C}$ confirms the existence of 1 . Crystal data: $\mathrm{C}_{40} \mathrm{H}_{60} \mathrm{Al}_{4}, M_{\mathrm{r}}=648.85$, triclinic, space group $P^{\overline{1}}$, $a=10.759(4) . h=10.913(3), c=18.027(5) \AA, \alpha=82.94, \beta=81.82 . ;=$ $66.88 . \forall=2116.6(12) \AA^{3}, Z=2$.

[11] J. Giusss. U. Schneider. R. Ahlrichs, C. Dohmeier, H. Schnöckel, J. Am. Chem. Sor. 1993. 115, 2402.

[12] The measurements were carried out at $+40,+70$, and $+78 \mathrm{C}$.

[13] If the NMR sample tube is left open for $1 \mathrm{~h}$, and then the sample is remeitsured at $+70 C$. two additional signals at $\delta=-9.3$ and -148.2 appear in the ${ }^{27} \mathrm{Al}$ NMR spectrum. The latter signal is consistent with the values postulated for monomeric $C \mathrm{p}^{*} \mathrm{Al}$.

[14] Because of the poor solubility of 1 , it is not possible to carry out a molar mass determination.

[15] N. Burford, B. W. Royan, R. E. v. H. Spence, R. D. Rogers, J. Chem. Soc Dahon Trans. 1990. 2111-2117.

[16] J. L. Atwood. S. K. Seale, J. Organomet. Chem. 1976, 114, 107-118.

[17] R. Nesper, I. Curda, Z. Naturforsch. B 1987, 42, 557.

[18] Crystal data of 2: $\mathrm{C}_{10} \mathrm{H}_{15}$ AlSe, $M_{r}=241.16$, tetragonal, space group $/ \overline{4}$ $a=b=12.144(1) . \quad c=14.373(2) \AA, \quad V=2119.7(4) \AA^{3} . \quad Z=8 . \quad \beta_{\text {calcd }}=$ $1.511 \mathrm{Mgm}^{-3}, \quad F(000)=976 . \quad \lambda=0.71073 \AA, \quad t\left(\mathrm{Mo}_{\mathrm{K} x}\right)=0.397 \mathrm{~mm}^{-1}$ The data were collected on a Stoe-Siemens-Huber diffractometer. Intensities of a rapidly cooled crystal with dimensions $0.6 \times 0.5 \times 0.4 \mathrm{~mm}$ in an oil drop [20] were collected at $-120^{\circ} \mathrm{C}$ by the $20 / \omega$ method in the range $8 \leq 2 t \leq 50$. Of the 1403 reflections collected, 1367 were unique and these were corrected for absorption by using a semiempirical procedure: highest minimum and maximum of the final difference Fourier synthesis: 0.32 and $-0.28 \subset \AA^{-3}$. respectively. $R 1=0.021, \| R 2=0.050$ (all data). The absolute structure was determined to $0.00(14)$ by a refinement of the Flack parameter (H. D. Flack. Acta Crivtallogr. Sect. A 1983, 39.876). Crystal data of 3: $\mathrm{C}_{10} \mathrm{H}_{15}$ AlTe, $M_{\mathrm{r}}=289.80$, tetragonal, space group $\overline{4}$. $u=s_{3}=12.430(2), c=14.546\{3) \AA, V=2247.4(7) \AA^{3}, Z=8, \quad \rho_{\text {calcd }}=$ $1.71 .3 \mathrm{Mgm}^{-3}, \quad F(000)=1120, j=0.71073 \AA, \mu\left(\mathrm{Mo}_{\mathrm{K} z}\right)=0.397 \mathrm{~mm}^{-1}$. The data were collected on a Stoe-Siemens-Huber diffractometer. Intensities of a rapidly cooled crystal with the dimensions $0.5 \times 0.4 \times 0.4 \mathrm{~mm}$ in an oil drop [20] were collected at $-120 \mathrm{C}$ by the $20 \%$ method in the range $8 \leq 20 \leq 55$. Of the 2370 reflections collected, 2278 were unicue and these were corrected for absorption by using a semiempirical procedure; highest minimum and maximum of the final difference Fourier synthesis: 0.39 and $-0.44 \AA^{-3}$. respectively. $R 1=0.017, \cdots R 2=0.042$ (all data). The absolute structure was determined to $0.03(2)$ by a refinement of the Flack parameter (H. D. Flack, Acta Cristallogt. Sect. A 1983, 39, 876). The values of $R 1$ and $\backsim R 2$ were defined as $R 1=\Sigma|| \mathrm{F}_{0}|-| \mathrm{F}_{\mathrm{c}} \mid /\left[\Sigma\left|\mathrm{F}_{0}\right| l\right.$ : $u R 2=\left\{\left[\sum w\left(F_{b}^{2}-F_{c}^{2}\right)^{2}\right] /\left[\sum m\left(F_{a}^{2}\right)\right]\right\}^{1: 2}$. The structures were solved by direct methods (SHELXS-90) [21] and refined by least-squares procedures (SHELXL-93) [22]. The hydrogen positions were refined according to a riding model in which the $\mathrm{CH}_{3}$ groups were allowed to rotate about their local threefold axis. Further details of the crystal structure investigations are available on request from the Director of the Cambridge Crystallography Data Centre, 12 Union Road. GB-Cambridge CB2 IEZ (UK), by quoting the full journal citation.

[19] M. Veith. Chem. Rev, 1990,90,3-16; see also T. Belgardt, H. W. Roesky, M. Noltemeyer, H.-G. Schmidt, Angew. Chent. 1993, 105. 1101, Angew Chwm. Int. Ed. Engl 1993. 32. 1056: K. M. Waggoner. P. P. Power, J. Am. Chem. Soc. 1991. 113, 3385

[20] T. Kottke. D. Stalke, J. Appl. Crysullogr. 1993, 26, 615.

[21] G. M. Sheldrick. Acta Cristallogr. Sect. A 1990, 46, 467-473.

[22] G. M. Sheldrick, SHELXL-93, Universität Göttingen, 1993.

[23] A. H. Cowley, R. A Jones. P. R. Harris, D. A. Atwood, L. Contreras, C. I. Burek. Angew. Chem. 1991, 103, 1164; Angen'. Chem. Imt. Ed. Engl. 1991 30. 1143.

\section{A Molecular Heterometal Amide with High Molecular Dynamics: Does the Lithium Atom Orbit?**}

\author{
By Michael Veith,* Michael Zimmer, \\ and Stefan Müller-Becker
}

\section{Dedicated to Professor Ulrich Wannagat on the occasion of his 70 th birthday}

Whilst the motion of lithium atoms in solids, such as, for example, in solid $\mathrm{Li}_{3} \mathrm{~N}$, has been thoroughly investigated and is generally accepted, ${ }^{[1]}$ many indications, but little concrete evidence for such a motion in molecules exists, in spite of much effort (see e.g. ref. [2]). Here we report on our studies of the heterometal amide $\left[\mathrm{Me}_{2} \mathrm{Si}\left(\mathrm{NSiMe}_{3}\right)_{2}\right]_{2} \operatorname{InLi}(\mathbf{1})$, an example of a class of molecular complexes that has still not been investigated in detail ${ }^{[3]}$ Compound $\mathbf{1}$ can easily be prepared according to Equation (a).

$2 \mathrm{Me}_{2} \mathrm{Si}\left(\mathrm{NSiMe}_{3}\right)_{2} \mathrm{Li}_{2}+\mathrm{InCl}_{3} \longrightarrow 3 \mathrm{LiCl}+\left[\mathrm{Me}_{2} \mathrm{Si}\left(\mathrm{NSiMe}_{3}\right)_{2} \mathrm{I}_{2} \mathrm{InLi}\right.$ (a)

According to the X-ray crystal structure analysis, ${ }^{[4]}$ (Fig. 1) the trivalent indium and the monovalent lithium atom in 1 are bound close together in a tricycle of four-membered rings $(\operatorname{In} \cdots \mathrm{Li}=2.748(9) \AA)$. The ${ }^{1} \mathrm{H},{ }^{13} \mathrm{C},{ }^{15} \mathrm{~N}$, and ${ }^{29} \mathrm{Si} \mathrm{NMR}$ spectra of 1 at room temperature in toluene (see Experimental Procedure) are not consistent with the molecular structure represented in Figure 1. Thus, only one reso-

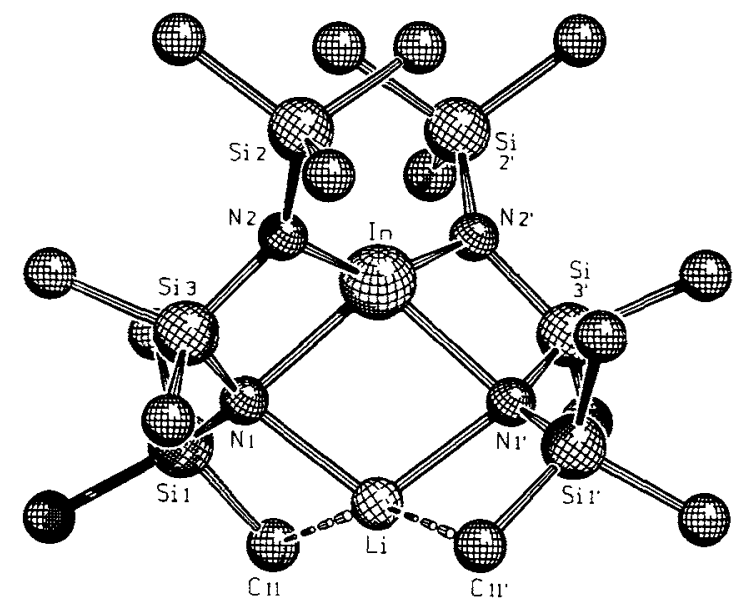

Fig. 1. Molecular structure of 1. Some important distances $[\AA]$ and angles []: $\mathrm{N} 1-\operatorname{In} 2.223(3), \mathrm{N} 2-\mathrm{In} 2.055(3), \mathrm{N} 1-\mathrm{Li} 2.064(6), \mathrm{N} 1-\mathrm{Si} 11.720(3)$. N1 - Si3 1.737(3), N2-Si2 1.714(3), N2-Si3 1.717(3), Li ․ C11 2.635(7); N1-In-N1' $95.2(1), \mathrm{N} 2-\mathrm{In}-\mathrm{N} 2^{\prime} 148.4(1), \mathrm{N} 1-\mathrm{In}-\mathrm{N} 276.2(1), \mathrm{N} 1-\mathrm{In}-\mathrm{N} 2^{\prime} 127.3(1), \mathrm{N} 1-\mathrm{Li}-\mathrm{N} 1{ }^{\prime}$ $105.4(3)$.

nance signal is found for both the dimethylsilylene and trimethylsilyl groups in the ${ }^{13} \mathrm{C}$ NMR spectrum, whereas a double set of signals would be expected because of the low $C_{2}$ symmetry of the molecule (the twofold axis passes through the two metal atoms).

If a toluene solution of $\mathbf{1}$ is cooled, ${ }^{1} \mathrm{H},{ }^{13} \mathrm{C}$, and ${ }^{29} \mathrm{Si}$ NMR spectra are obtained at lower temperature (as an ex-

[*] Prof. Dr. M. Veith, M. Zimmer, Dr. S. Müller-Becker Institut für Anorganische Chemie der Universität Postfach 11 50, D-66041 Saarbrücken (FRG) Telefax: Int. code $+(681) 302-3995$

$\left[{ }^{* *}\right]$ This work was supported by the Deutsche Forschungsgemeinschaft and the Fonds der Chemischen Industrie. 
ample ${ }^{13} \mathrm{C}$ NMR spectra are reproduced in Fig. 2) with twice (or one and a half times) the number of signals as expected from the crystal structure. An activation energy of $44.3 \mathrm{~kJ} \mathrm{~mol}^{-1}$ can be determined from analysis of the coalescence temperature and the signal splitting derived from heteronuclear NMR spectra. ${ }^{[5]}$ The signal of the trimethylsilyl groups shifted to high field shows unusual behavior: With decreasing temperature a selective broadening is found, a phenomenon that can be explained by a rotation barrier about the $\mathrm{Si}-\mathrm{N}$ bond, which is also found for trimethylsilyl groups of other molecules. ${ }^{[6]}$ On examination of the solidstate molecular structure (Fig. 1), it becomes apparent that the reason for the rotational barrier of this one trimethylsilyl group is due to lithium methyl contacts (dotted lines); at the same time, this finding allows the assignment of the resonance signals.

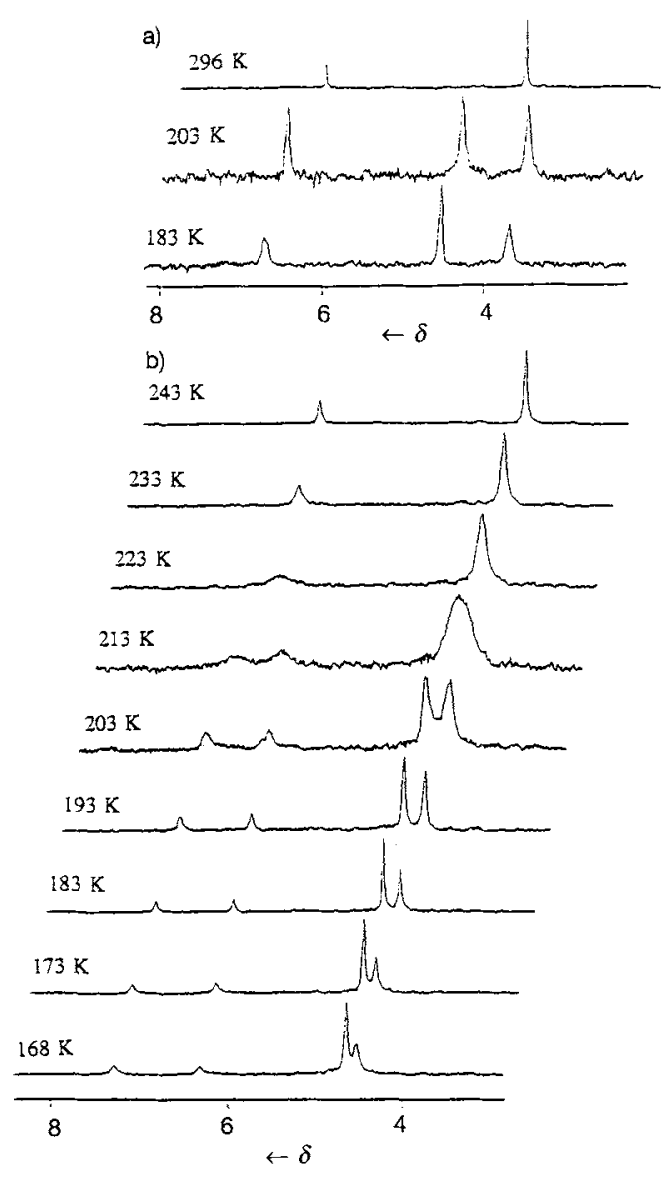

Fig. $2 .{ }^{13} \mathrm{C}$ NMR spectra $(50,3 \mathrm{MHz})$ of 1 a) in hexane at three temperatures and $\mathrm{b})$ in tolvene between 243 and $168 \mathrm{~K}$

Temperature-dependent measurements of the spin-lattice relaxation $T_{1}$ of the ${ }^{7} \mathrm{Li}$ isotope give the expected curve shape on plotting the graph with a minimum at $203 \mathrm{~K}$. Analysis of the Arrhenius plot gives a value of $13.8 \mathrm{~kJ} \mathrm{~mol}^{-1}$ for the high-temperature end; this value is typical for methyl and trimethylsilyl rotations about threefold axes. ${ }^{[7]}$ It implies several coupled migrations in the molecule and suggests that the lithium atom is involved in these.

The series of temperature-dependent ${ }^{13} \mathrm{C}$ NMR spectra shown in Figure 2 were also repeated for significantly higher and lower concentrations of $\mathbf{1}$ in toluene (about five- and tenfold), without any observable changes occurring in the comparable spectra. We conclude from this that an intermolecular process is unlikely to be the reason for the observed spectra at room temperature. Clearly all findings are consistent with a higher "average" point symmetry of the molecule at room temperature. Instead of the $C_{2}(2)$ symmetry in the crystal lattice, in which the molecules are exclusively bound by van der Waals contacts, $D_{2 \mathrm{~d}}(\overline{4} 2 m)$ symmetry must be ascribed to the whole molecular unit in solution. The increase in symmetry is clearly determined by dynamic phenomena in which lithium, as the lightest of the atoms (if one neglects the covalently bonded hydrogen atoms), plays a special role.

After exclusion of an intermolecular process only an intramolecular and a dissociative mechanism remain. We consider the formation of an ion pair of the type $\mathrm{Li}^{+}\left[\left\{\mathrm{Me}_{2} \mathrm{Si}\left(\mathrm{NSiMe}_{3}\right)_{2}\right\}_{2} \mathrm{In}\right]^{-}$in solution, which would involve an anion with $D_{2 \mathrm{~d}}$ symmetry, to be unlikely in toluene due to the large amount of energy required to break the $\mathrm{Li}-\mathrm{N}$ bond and to the relatively low expected solvation energy. Furthermore, analogous ${ }^{1} \mathrm{H}$ and ${ }^{13} \mathrm{C}$ NMR spectra with few signals are obtained when $\mathbf{l}$ is dissolved in nonpolar hexane (Fig. $2 \mathrm{a}$ ). Here too, a splitting of the $\mathrm{Me}_{3} \mathrm{Si}$ signal is observed at lower temperatures. Thus, identical activation energies $\left(44.3 \mathrm{~kJ} \mathrm{~mol}^{-1}\right)$ to those in toluene are determined. In contrast to the spectra in toluene (dipole moment: $0.36 \mathrm{D}$ ), in hexane the signal for the dimethylsilyl group does not split up to the freezing point of the solvent. The molecule must therefore retain a residual mobility in nonpolar solvents, which is suppressed in polar toluene, because the static molecule itself is strongly dipolar.

We believe that the observed spectra can best be explained by an intramolecular dynamic process. In this context, two processes can be discussed: One possibility is an essentially oscillating motion of the lithium atom in an orbit around the center of the molecule, which can be described as a indiumcentered $\mathrm{N}_{4}$-bisphenoid (Fig. 3). A conceivable alternative
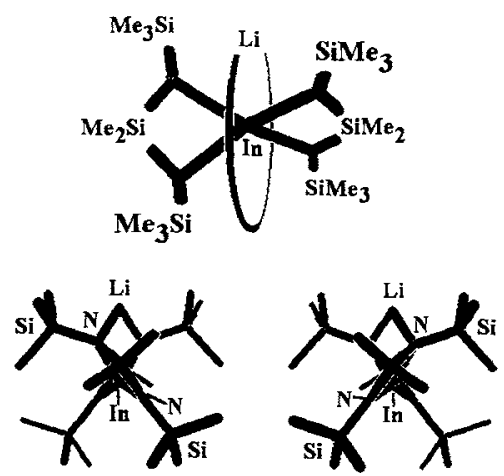

Fig. 3. Top: An intramolecular model for the "lithium migration". Bottom: The two structures of 1 found in the crystal (view orthogonal to the upper drawing). Their interconversion could explain the "residual mobility" of 1 in hexane.

would be that the $\mathrm{Me}_{2} \mathrm{Si}\left(\mathrm{NSiMe}_{3}\right)_{2}$ ligands move disrotatory around a pseudo Si3-Si3' axis (see Fig. 1); thus, the two metal atoms remain in their positions. Molecular dynamic model calculations ${ }^{[8]}$ and the consideration of group vibrations show, however, that both processes are basically the same and that only a different reference point has been chosen. Moreover, this model explains the nature of the abovementioned residual mobility in hexane below $220 \mathrm{~K}$. In this 
case the lithium atom is now only in contact with two nitrogen atoms at which inversions take place. In the extreme case this leads to the two molecules represented in the lower half of Figure 3. These are enantiomers and both crystallize together (in the crystal structure they are connected by inversion centers).

Solid-state NMR spectra were also obtained for 1 . The central line of the Magic Angle Spinning (MAS) ${ }^{7} \mathrm{Li}$ NMR spectrum $(77.7 \mathrm{MHz})$ of 1 at room temperature consists of two components: a broad resonance signal showing the typical quadrupolar splitting obtained in MAS experiments for quadrupolar nuclei ${ }^{[9]}(586 \mathrm{~Hz})$, as well as a quasi-superimposed relatively sharp resonance with a half-width of about $120 \mathrm{~Hz}$. If a second spectrum of the same sample is recorded at $116.5 \mathrm{MHz}$, the peak separation of the outer peaks is reduced, which is consistent with a quadrupolar effect. The sharp resonance signal at $296 \mathrm{~K}$ combines about $8 \%$ of the total intensity including the side bands and should be due to "readily mobile" lithium atoms. ${ }^{[10 I}$ Whether the signal is due to a partial "lithium dynamic" as a result of lattice vibrations in 1 or whether it is caused by a small amount of some impurity still needs to be clarified by further investigations.

\section{Experimental Procedure}

Indium chloride $\{0.7 \mathrm{~g}, 3.2 \mathrm{mmol})$ in diethyl ether $(5 \mathrm{~mL})$ was added to two molar equivalents of $\mathrm{Me}_{2} \mathrm{Si}\left(\mathrm{NSiMe}_{3}\right)_{2} \mathrm{Li}_{2}[11]$ in $n$-hexane $(25 \mathrm{~mL})$ and stirred for $6 \mathrm{~h}$ at room temperature. The suspension was filtered and the solution concentrated: during this process crystals of the ether adduct of 1 formed. The ether was eliminated from the compound in the subsequent sublimation (70$80 \mathrm{C}$ bath temperature $/ 10^{-3}$ Torr) and $1.37 \mathrm{~g}(73 \%)$ of 1 were obtained as colorless crystals (m.p. $142 \mathrm{C}$ ). Correct analyses and mass spectra. Chemical shifts of 1 in solution ( $200 \mathrm{MHz}$ [D $\mathrm{D}_{8}$ toluene. $296 \mathrm{~K}$. TMS): ${ }^{1} \mathrm{H}$ NMR: $\delta=0.18$ (s. 36H. SiMe $\left.)_{3}\right), 0.33\left(\mathrm{~s}, 12 \mathrm{H} . \mathrm{SiMe}_{2}\right):{ }^{13} \mathrm{C} \mathrm{NMR}\left(\left[\mathrm{D}_{8}\right]\right.$ toluene $): \delta=4.2(\mathrm{~s}, 12 \mathrm{C}$. $\left.\mathrm{SiMe}_{3}\right), 6.6$ (s. $\left.4 \mathrm{C}, \mathrm{SiMe}_{2}\right),{ }^{13} \mathrm{C}$ NMR (hexane) $\dot{\delta}=3.9$ (s. $\mathrm{SiMe}_{3}$ ), 6.4 (s, $\mathrm{SiMe}_{2}$ ): ${ }^{29} \mathrm{Si}$ NMR: $\delta=-0.55$ (s. SiMe $\left.\mathrm{SM}_{2}\right)-5.80$ (s. $\left.\mathrm{SiMe}_{3}\right) ;{ }^{15} \mathrm{~N} \mathrm{NMR}$ $\left(\mathrm{CH}_{3} \mathrm{NO}_{2}\right.$ ext. $): \dot{\delta}=-308.5\left(\mathrm{~s}, b_{22}=10 \mathrm{~Hz}\right) ;{ }^{7} \mathrm{Li} \mathrm{NMR}$ (ext. standard: $\mathrm{LiCl}$ $\left.\mathrm{D}_{2} \mathrm{O}\right): j=3.0\left(\mathrm{~s} . h_{12}=5.7 \mathrm{~Hz}\right)$. Chemical shifts of 1 in the solid state $(200 \mathrm{MHz}, 296 \mathrm{~K}$, sec. standard: ddamantane, TMS $=0),{ }^{13} \mathrm{C}$ NMR: $\delta=5.8$ $\left(b_{12}=85 \mathrm{~Hz}\right)$. ' Li NMR fext. standard: LiCl $): \delta=1.0$ [12].

Received: May 3, 1993

Revised version: June 28, 1993 [Z 6051 IE] German version: Angew, Chem. 1993. 105, 1771

[1] A. Rabenau, Nach. Chen. Tech. Lab. 1978, 26,310; P. Hartwig, W. Weppner. W. Wichelhaus. A. Rabenau. Angew. Chem. 1980, 92, 72; Angew. Chem. Int. Ed. Engl, 1980, 19, 74

[2] F. Pauer, J. Rocha, D. Stalke, J. Chem. Sor. Chem. Conmun. 1991, 1477.

[3] M. Veith. S. Müller-Becker in The Chemisrry of Inorganic Ring Systems (Ed.: R. Steude1). Elsevier, Amsterdam, 1992. p. 125.

[4] Crystal data for 1: monoclinic. space group $C 2 / c, a=11.814(9), b=$ 16.986(20). $r=16.719(20) \AA, \beta=104.63(9)^{\circ}, V=3246 \AA^{3}, Z=4, \mu=$ $9.14 \mathrm{~cm}^{-1}$. Siemens-AED2 diffractometer, $\omega-\theta$ scan, 2109 reflections of which 81 with $F_{0}<M K>2 \sigma_{F}, 20_{\max }=45^{\circ}$; measurement temperature $293 \mathrm{~K}$. Structure solution by Patterson methods, $\mathrm{H}$ atom positions idealized $(\mathrm{C}-\mathrm{H}=1.08 \AA$, H-C-H $=109.5 ; 153$ parameters (all non-hydrogen atoms with anisotropic temperature factors). $R=0.033\left(R_{w}=0.038\right.$; weighting scheme: $\left.1=1.00 /\left(\sigma_{F}^{2}+0.006384 F^{2}\right)\right)$. Maximum and minimum residual electron density: 0.27 and $-0.80 \mathrm{e} \AA^{-3}$. Programs used: SHELX 86 [13] and SCHAKAL [14]. Further details of the crystal structure investigation may be obtained from the Fachinformationszentrum Karlsruhe, Gesellschaft für wissenschaftlich-technische Information mbH, D-76344 Eggenstein-Leopoldshafen (FRG) on quoting the depository number CSD-57682. the names of the authors, and the journal citation.

[5] J. Sandström. Dynamic NMR Spectroscopy. Academic Press. New York, 1982, p. 96 .

[6] M. Zimmer, dissertation. Universität des Saarlandes, 1993.

[7] D. W. Aksnes. K. Ramstad, Magn. Reson. Chem. 1988, 26. 1086.

[8] HYPERCHEM 3.0. Autodesk, Inc. USA 1993, parameters modified by M. Veith.

[9] R. K. Harris, A. C. Olivieri, Progr. Nucl. Magn. Reson. Spectrosc. 1992. 24. 435 .
[10] A selective representation of the two components can be obtained by inversion-recovery experiments because of the very different relaxation behavior.

[11] W. Fink, Chem. Ber. 1963, 96, 1071

[12] The ${ }^{3} \mathrm{H},{ }^{7} \mathrm{Lj},{ }^{13} \mathrm{C},{ }^{15} \mathrm{~N}$, and ${ }^{29} \mathrm{Si}$ NMR spectra were recorded with a Bruker $200 \mathrm{MHz}$ spectrometer, the solid-state NMR spectra were recorded on a MSL 200 (Bruker). Airtight Kel-F inserts were used in 7-mm-MAS rotors for the sample preparation. The $T_{\mathrm{t}}$ measurements were carried out according to standard inversion-recovery methods.

[13] G. M. Sheldrick, Program for Crystal Structure Determination. Universitat Göttingen, 1986.

[14] E. Keller, SCHAKAL-88. Fortran Program for the Graphical Representation of Molecular and Crystallographic Models, Freiburg, 1988.

\section{Palladium-Catalyzed Arylation of Tetrasubstituted Double Bonds: A Simple Synthesis of Annelated Propellanes**}

\author{
By Gerald Dyker,* Jutta Körning, Peter G. Jones, \\ and Peter Bubenitschek
}

As a result of their special topology propellanes have stimulated a multitude of syntheses and investigations into their chemical and physical properties. ${ }^{11}$ The benzoannelated [4.4.4]propellane $\mathbf{1}^{[2]}$ is of particular interest in this respect, as in this compound a hexaarylethane ${ }^{[3]}$ structure is stabilized by triple clamping. However, the increased ring strain caused by reducing the size of the propellane rings can cause destabilization of the central single bond to reoccur. The highly strained dehydrotriptycene $\mathbf{2}-\mathrm{a}$ [2.2.2]propellane-represents an extreme example and so far all attempts at its synthesis have been unsuccessful. ${ }^{[4]}$ We report here on a rational entry to aryl-annelated [3.3.n]propellanes with $n=2$, 3 , and 4 .

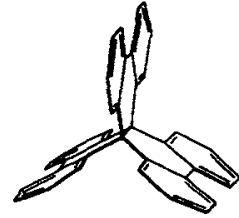

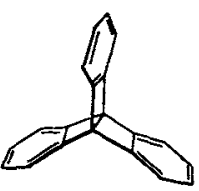

2
The hexacyclic hydrocarbon 7 is the key compound in the synthesis of the desired propellanes and can be prepared in one step from acenaphthylene and 1,8-diiodonaphthalene by a palladium-catalyzed annelation. ${ }^{[5]}$ Formation of the [3.3.3]propellane 3, which contains a threefold symmetry axis, was achieved in a single step by way of a second palladium-catalyzed annelation, this time with monoiodonaphthalene $\mathbf{5}$ (Scheme 1) ${ }^{[6]}$ The use of 1,8-diiodonaphthalene in

[*] Dr. G. Dyker, Dipl.-Chem. J. Körning

Institut für Organischen Chemie der Technischen Universität

Hagenring 30, D-38106 Braunschweig (FRG)

Telefax : Int. code + (531)391-5388

Prof. Dr. P. G. Jones, Dipl.-Chem. P. Bubenitschek

Institut für Anorganische und Analytische Chemie der Technischen Universität Braunschweig (FRG)

[**] Transition Metal-Catalyzed Annelation Reactions, Part 6. This work was supported by the Deutsche Forschungsgemeinschaft and the Fonds der Chemischen Industrie. Part 5: Angew. Chem. 1994, 106. No. 1: Angew. Chem. Int Ed. Engl. 1994, 33, No. 1. 